\title{
Commentary: Never PROMIS more than you can deliver
}

\author{
Sue X. Wang, MD, SangMin Kim, BS, and \\ M. Blair Marshall, MD
}

Patient-reported outcomes (PROs) provide critical information regarding postoperative functional status and quality of life. ${ }^{1}$ In their prospective cohort study of patients with non-small-cell lung cancer undergoing surgery, Heiden and colleagues ${ }^{2}$ collected data on physical function, pain interference, and dyspnea severity using the National Institutes of Health Patient-Reported Outcomes Measurement Information System (PROMIS)-a low-cost, web-based, validated assessment platform that is suitable for widespread adoption. ${ }^{3}$

We would like to commend the authors for their thoughtful study design and analysis. Heiden and colleagues $^{2}$ navigated logistical and institutional challenges to collect PRO data preoperatively $(\mathrm{n}=246)$ and at 1 month $(\mathrm{n}=196), 6$ months $(\mathrm{n}=113)$, and 12 months $(\mathrm{n}=72)$ postoperatively. At each visit, patients were given PROMIS surveys on pain, physical function, and dyspnea to complete in approximately 3 minutes total. PROMIS data were merged with the authors' institutional Society of Thoracic Surgeons database to correlate with patient demographic characteristics, tumor characteristics, and perioperative outcomes. The study population included $42.2 \%$ stage I disease. Of note, there were no data on whether or not patients underwent adjuvant or neoadjuvant treatment. This is a potential confounder. The authors conclude that whereas patients undergoing thoracotomies $(63.5 \%)$ initially report worse pain and physical function, this normalizes by 6 months following surgery. They attribute the high rate of thoracotomies to surgeon preference, heavily calcified hilar lymph nodes in their study population, and

\footnotetext{
From the Division of Thoracic Surgery, Department of Surgery, Brigham and Women's Hospital, Boston, Mass.

Disclosures: The authors reported no conflicts of interest.

The Journal policy requires editors and reviewers to disclose conflicts of interest and to decline handling or reviewing manuscripts for which they may have a conflict of interest. The editors and reviewers of this article have no conflicts of interest.

Received for publication Dec 3, 2021; revisions received Dec 3, 2021; accepted for publication Dec 3, 2021; available ahead of print Dec 8, 2021.

Address for reprints: Sue X. Wang, MD, Division of Thoracic Surgery, Brigham and Women's Hospital, 75 Francis St, Boston, MA 02115 (E-mail: swang53@bwh. harvard.edu).

J Thorac Cardiovasc Surg 2022;164:627-8

$0022-5223 / \$ 36.00$

Copyright (c) 2021 by The American Association for Thoracic Surgery

https://doi.org/10.1016/j.jtcvs.2021.12.009
}

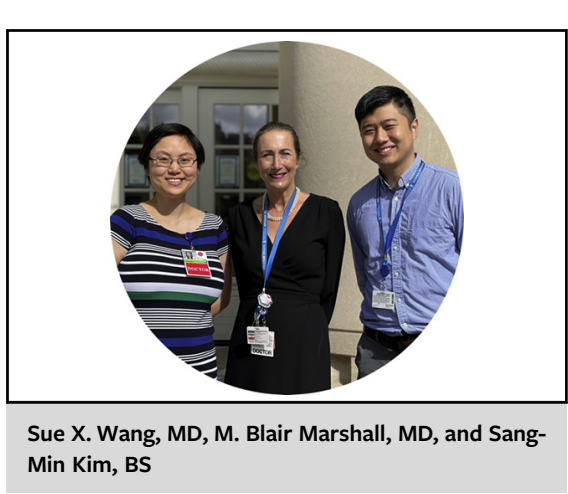

CENTRAL MESSAGE

Patient-reported outcomes are powerful tools to inform surgeons and patients about quality of life after thoracic surgery. Further validation is needed to support the authors' conclusions.

a complex academic cohort with advanced-stage disease. Regardless of approach or extent of resection (lobectomy vs sublobar resection), dyspnea persisted for at least 1 year at similar levels of severity.

A major limitation of the study is its considerable attrition. Although 334 patients completed at least 1 PROMIS assessment, there was a progressive drop off in responses over time, with only $21.5 \%(\mathrm{n}=72$ out of 334$)$ of patients responding at 12 months after surgery. Considering the high lobectomy rate $(72.5 \%)$ in this study, we note that there are only 12 patients responding in the sublobar resection cohort at 12 months following surgery. The numbers speak for themselves: This study lacks power. Further validation is needed. Future studies should utilize online survey administration to capture nonlocal patients who elect for follow-up closer to home.

We acknowledge that PROMIS holds promise, but much work remains to be done before PROs can become a quality metric for reimbursement. The fact that there will always be a role for maximally invasive surgery further complicates the question of reimbursement. Should surgeons be penalized for open lung resection? Although we are strong proponents of minimally invasive techniques, we acknowledge that there are cases where a thoracotomy is indicated by technical challenges or oncologic principles. 
Indeed, PROs in the thoracotomy cohort for pain and physical function recovered to baseline by 6 months. ${ }^{2}$ From the perspective of PROs, in the long term, the operative approach does not appear to make a difference. ${ }^{2,4}$

Surgeons must look to PROs to set evidence-based expectations around postoperative quality of life. ${ }^{1}$ Both subjective and objective measures fulfill core components of informed consent, and we foresee the increased recognition and incorporation of PROs into routine clinical practice.

\section{References}

1. Medbery RL, Fernandez FG, Khullar OV. Patient-reported outcomes: time to integrate into outcomes reporting? Semin Thorac Cardiovasc Surg. 2019;31: 856-60. https://doi.org/10.1053/j.semtcvs.2019.05.030

2. Heiden BT, Subramanian MP, Liu J, Keith A, Engelhardt KE, Meyers BF, et al. Long-term patient-reported outcomes after non-small cell lung cancer resection. J Thorac Cardiovasc Surg. 2022;164:615-26.e3.

3. Gershon RC, Rothrock N, Hanrahan R, Bass M, Cella D. The use of PROMIS and assessment center to deliver patient-reported outcome measures in clinical research. J Appl Meas. 2010;11:304-14.

4. Khullar OV, Rajaei MH, Force SD, Binongo JN, Lasanajak Y, Robertson S, et al. Pilot study to integrate patient reported outcomes after lung cancer operations into the Society of Thoracic Surgeons database. Ann Thorac Surg. 2017;104:245-53. https://doi.org/10.1016/j.athoracsur.2017.01.110 